\section{Regimes of Visibility: Hanging Out in Brussels' Public Spaces}

Space and Culture

$1-13$

(C) The Author(s) 2018

Reprints and permissions: sagepub.com/journalsPermissions.nav DOI: 10.1 I $77 / 1206331218773292$ journals.sagepub.com/home/sac

(SAGE

\author{
Mattias De Backer'
}

\begin{abstract}
Visibility is an important characteristic of public space. According to Brighenti, control and recognition can be understood as two opposing outcomes of visibility. These two modes are studied empirically through the use of data from a research project with young people in Brussels. This article zooms in on young people's appropriation of a space for themselves and their negotiation of control and investigates what role (in)visibility plays in the micropolitics of these practices. It concludes that these regimes of visibility can be easily found in young people's behavior in public space. However, they are not mutually exclusive: They easily transform into the other or present themselves simultaneously.
\end{abstract}

\title{
Keywords
}

young people, public space, Brussels, visibility, control, appropriation

\section{Introduction}

In the past four to five decades, quite some scholars have reflected on the specificity of public space. Criteria such as accessibility, diversity, or control have been advanced as key components for defining it. ${ }^{1}$ Only some have focused on the specific role that is played by visibility, as a social category and as a driver in public space interactions. Arendt (1958/1998), for instance, argues that publicness can only be achieved if there is "intervisibility" and "appearance":

It means, first, that everything that appears in public can be seen and heard by everybody and has the widest possible publicity. For us, appearance - something that is being seen and heard by others as well as by ourselves - constitutes reality. (p. 50)

Microsociologists such as Goffman (1963) and Lofland (1998) have collected evidence about the importance of visibility, and specifically the glance, in regulating stranger interaction: "the eye has a uniquely sociological function: the union and interaction of individuals is based upon mutual glances" (Goffman, 1963, p. 93). Probably the most comprehensive work in investigating and conceptualizing visibility has been undertaken by Andrea Brighenti (2007, 2008, 2010a, $2010 b$ ). It has been his endeavour to describe both the actual phenomena of visibility in public space and the characteristics of visibility as a workable category in the social sciences.

\section{'KU Leuven, Leuven, Belgium}

\section{Corresponding Author:}

Mattias De Backer, Department of Criminology, KU Leuven, H. Hooverplein 10, 3000, Leuven, Belgium.

Email: mattias.debacker@kuleuven.be 
In this article, I will take up the challenge formulated by Brighenti (2007), regarding the study of actual phenomena of visibility, first by discussing other recent work on the topic and second by bringing original data from fieldwork in Brussels to the table. To structure the data and the state of the art, I will follow Brighenti's useful suggestion that visibility presents itself in two outcomes: recognition and control. The former refers to acts of resistance and empowerment by minority groups against the mainstream, for instance, how they claim a space to make themselves visible. The social can be perceived as a continuum between lower and upper thresholds of "fair visibility." Below the lower threshold one is socially excluded (invisible). In the latter presentation, visibility relates to control: "[t]he mere fact of being aware of one's own visibility status - and not the fact of being under actual control—effectively influences one's behaviour" (Brighenti, 2007, p. 336). Although the author does not reiterate that claim in later work, Brighenti (2007) states that "recognition and control are understood and explained as two opposing outcomes of visibility" (p. 323). In this article, I will argue that control and recognition are heavily intertwined - that is, they can happen simultaneously and that one can transform into the other.

Visibility-as-control of course plays a crucial role in Foucault's (1977) idea of panoptic surveillance. The major effect of the panopticon is "to induce in the inmate a state of conscious and permanent visibility that assures the automatic functioning of power" (p. 201). Here, modes of visibility are produced by power to control society. But, as Gordon (2002) argues, the inverse is also true: "the very same power that produces visibility is concomitantly dependent upon it" (p. 125). Also relevant in this regard is the work of Newman (1972) and others on architectural crime prevention strategies and, for instance, the use of street lighting (to make visible). Particularly in surveillance studies, the concept of visibility has received much attention (Koskela, 2000). We can refer in this regard to Cook and Whowell's (2011) study of public space policing and Coaffee, O'Hare, and Hawkesworth's (2009) article on the role of subtle visibility techniques in counterterrorism measures. Finally, both in the development of communication media (Thompson, 2005) and of the Internet and its virtual spaces (Hatuka \& Toch, 2017) situations of asymmetrical visibility are produced that are increasingly perceived as "normal": "The idea of urban public space as a place that provides relative anonymity is shrinking" (Hatuka \& Toch, 2017, p. 13). In Allen's (2006) study of public space management in commercial areas, finally, an analysis is presented that focuses on "the quieter, more impalpable [and less visible] registers of power" (p. 454).

Visibility-as-recognition refers to the claiming and appropriation of space by subaltern groups. Such appropriations, as acts of resistance against a dominant order, are seldom simply tolerated (Frers \& Meier, 2017). Cancellieri and Ostanel (2015) find that migrants in Italy are being accused of surpassing the "upper threshold of correct visibility" (p. 499). In their study of people's perceptions of and opinions on street drinking in Lancaster (United Kingdom), Dixon, Levine, and McAuley (2006) find that respondents say drunkards in public space distort the private/public distinction, which limits access to and free use of public space for other citizens. This mode of visibility is also a daily reality for many women who, when entering public space, subject themselves to the male gaze (Massey, 1994). The main reason for women's feelings of insecurity is exactly their "exaggerated visibility" (Brown, 1998, p. 218). Similarly, to wear religious symbols or to cover one's body is an (often inverse) expression of visibility as recognition (Göle, 2002 , 2011). In many studies of homophobic violence, it is indicated that public space is governed by moral statements about overt - that is, visible - "homosexual conduct" such as handholding as being reproachable (Millbank, 2002). This often results in practices of hiding among homosexuals and lesbians (Valentine, 1995). However, in some cases, lesbians expressly mix in a heterogeneous public space to be visible to one another. This somewhat deconstructs the common link between overt visibility and recognition and political legitimacy (Podmore, 2001). Of course, when considering the general nature of public space, also, invisibility plays a crucial role in the principles of stranger interaction (Goffman, 1963; Lofland, 1998), as urban ethnographers 
will find while doing covert observation and dérives in public space (Lofland, Snow, Anderson, $\&$ Lofland, 2006). Many urban undesirables, such as homeless people, will (try to) benefit from the possibility to remain invisible in public space (Langegger \& Koester, 2016).

This brings us to the heart of this special issue. The two modes of visibility (recognition and control) proposed by Brighenti (2007) are necessary to better understand what takes place in public space and why. "Publicness" is an ongoing process, a creation of practices rather than a preestablished frame (Göle, 2002). In this frame, visibility is an important angle through which to look at mundane and everyday acts of political, cultural, symbolic, and social agency. Many small acts are micropolitical, in the sense that they may be covert, tacit, innocuous, or unintentional, but they still are an expression of a political stance and a practice of protest.

In this article, I will engage with data from ethnographic fieldwork undertaken in Brussels, to study two youth practices: the appropriation of a space for oneself and the negotiation of control infrastructures and practices. This brings me to the following research questions: (1) how do young people appropriate spaces for themselves in public space, (2) how do they negotiate control infrastructures and practices, and (3) what role does (in)visibility play in the micropolitics of appropriation and control negotiation?

\section{Methodology and Case Study}

The fieldwork on which this article draws took place in five neighborhoods in Brussels between 2013 and 2016. It involved countless hours of observation in various public spaces, as well as loosely structured interviews and focus groups in which 48 young people between 11 and 25 years old were interviewed. In addition, time was spent with young people in the context of youth club activities, youth camps, as well as during walks in their neighborhoods. Some of the fieldwork activities were documented by a filmmaker, which led to the documentary La Ville, Mon Espace ${ }^{2}$.

Brussels is by far the biggest and most dense city of Belgium. In the hierarchies of both poorest and wealthiest municipalities in the country, Brussels' municipalities score high. This is indicative of an enormous abyss between the rich and the poor within the same city region. Brussels is not only socially but also spatially divided following topographic lines with wealthier areas literally rising above poorer neighborhoods (Corijn \& Vloeberghs, 2009). The defining demographic figure of the city is the crescent shape in the northwest side of the city. In it are those neighborhoods that can be distinguished by the concentration of poverty, unemployment, high density, high ethnic diversity, low income, little education, low-quality housing and public investments, large and young families, and so on.

The fieldwork for this research took place in the Jacht-Jourdan, Chicago, Kuregem, SintGuido, and Peterbos neighborhoods. These areas were not necessarily chosen with the aim of truly comparative research; rather, the objective was to give an insight in the life-world of young urbanites and their experiences, emotions, actions, habits, and movements cutting through the various demographic differences. Jacht-Jourdan is a lower-middle-class area with an average income just below the Brussels Region's average. It is rather diverse, in terms of ethnicity, but has lower proportions of North Africans, compared with areas such as Kuregem or Historisch Molenbeek. The Chicago area consists of two very dense neighborhoods on both sides of the canal. The area is characterized by relatively low education level, high unemployment $(40 \%),{ }^{3}$ and an economic standstill. Moroccans are the largest minority in the area. In terms of housing, the situation is dire. The neighborhood has rather large families living in small and old houses.

Kuregem is similar to the Chicago neighborhood. It has $40 \%$ unemployment and $55 \%$ youth unemployment. Family size is highest in Kuregem, compared with the whole city region. And together with the Chicago area the population is the youngest in the region. Kuregem is an area that houses many Moroccan inhabitants, but there is also a large presence of sub-Saharan Africans. With its small houses, little public space, and high density, the situation in Kuregem for young people is dramatic. 
Sint-Guido, officially termed Anderlecht-Centrum-Wayez, has an average income that ranks only slightly higher than the very poor Kuregem and Chicago areas, but it has better housing. Peterbos, finally, is a lower-middle-class residential area. Central in the neighborhood is a series of high-rise social housing blocks on which my fieldwork focused for this project. In many interviews, it was indicated that the Peterbos, Chicago, and Kuregem neighborhoods share a strong sense of community among the inhabitants.

Eventually, 48 young people were interviewed, either in the context of one-on-one interviews or in focus groups. These encounters took place as a result of ethnographic work in two youth clubs, which I joined as a researcher and volunteer youth worker, and workshops in a secondary school. I also went on two youth camps as a cook and logistics helper, in which context I met young people with whom I did n't do formal interviews but had many informal chats. In the research, I focused on young people between 10 and 25 years old, an age spread that is not uncommon in youth research (see Travlou, 2003).

In terms of methodology, I developed a scenario consisting of the following elements: (1) exploratory observation including the mapping of youth spaces and of control infrastructures, (2) ethnographic fieldwork with a local partner (youth club or secondary school), (3) focus groups, (4) mental maps drawn by the participants (inspired by Lynch, 1981), (5) individual interviews, (6) a neighborhood walk where participants showed their favorite places in the neighborhood, and (7) longer observations undertaken by myself in a dérive style (Coverley, 2010; Debord, 1958). This sequence, obviously, was dependent on the circumstances of fieldwork in every case study, as well as on the different agendas of the local actors involved.

\section{Control as a Regime of Visibility}

In this section, I will explore Brussels' young people's negotiation of and opinions about control. I will first pay attention to the more overt forms of control, such as police practices and CCTV cameras, after which I will discuss control exerted through ordinary objects such as fences, benches, and so on. I will make three points: (1) Contrary to some other commentators, I found that young people in Brussels are not particularly preoccupied with hiding from plain sight. Sometimes on the contrary: Hanging out is often an extremely social activity that takes place in the middle of the street activity. (2) A large majority of Brussels youngsters is surprisingly tolerant toward control. This, however, is not the case for those young people who are controlled on a daily basis. They feel targeted, stigmatized, and harassed by the authorities. (3) It would be wrong to phrase control only in terms of visibility. We could probably view control as a spectrum with surveillance and police practices on the one end and much less visible forms of control on the other. Such less visible controls still have an important effect on behavior in public space, but this is usually felt rather than understood.

In the beginning of my research project, I engaged in an exploratory mapping exercise. I compared Kuregem, an area that has been framed in national media as a no-go area, with a very high density and a population dominated by North and sub-Saharan Africans, with Jacht-Jourdan, which is an ethnically mixed lower-middle-class area in the vicinity of the European Institutions. The aim of the exercise was to see if youth geographies and control geographies tend to be different or if they overlap. For this purpose, I mapped popular youth spaces in those neighborhoods and the locations of CCTV cameras.

While one would expect that young people avoid control, this proved not to be the case. The Jourdan square in Jacht-Jourdan, which has countless (often privately operated) security cameras, is also quite a popular hanging spot for teenagers in the area. Similarly, the Lemmens Square in Kuregem is often used by young people hanging out, while several cameras are directed straight at the square, and police patrols often drive by. The same goes for the vicinity of the European Parliament, where young people do not mind hanging out in an intensely surveilled 
environment, including an overt police and private security presence. My findings suggest that young people do not mind putting themselves squarely in the field of visibility and "assume responsibility for the constraints of power," as Foucault (1977,pp. 202-203) puts it. To be in public space implies to be subjected to control. Young people take this for granted and inscribe these power relations in their behavior.

Also in the interviews, a large majority of the participants expressed a favorable opinion on CCTV cameras. They stressed the preventive efficacy of the devices, for instance. Meryem (13, female): "I think it is normal that there are cameras. For pickpockets or burglars." Many also say that these technologies don't affect their behavior at all. Monifa (18, female): "I don't really care. I don't act differently when there are cameras." Although some see the limits to this technology:

Chaimaa (21, female): They do not tackle the problem. Wrongdoers would simply go to another place. They spend money on them and it doesn't change offenders' attitudes. It would not make them think. It will only teach them that that's not a place they ought to be and that they have to go elsewhere.

In general, girls and young women are more in favor of cameras due to issues of security. But they are also less concerned about control because, contrary to boys, they are not inclined to "mess around."Nouhaila (19, female): Girls do not hang out in the street; we move from A to B. But I can imagine that for boys, when there is a camera in a place where they hang out, it isn't agreeable.

Faiza and Elizabeth (both 18, female) make an interesting point. They say "cameras won't make a difference because we are already constantly controlled." In other words, these girls think that young people are tolerant toward control because they are used to being controlled in most areas of their lives anyway.

However, I think the opposite is true. Young people with a more critical (or straight-out angry) viewpoint on the matter usually experience control, harassment, and intimidation by the police on a daily basis. They are frequently subjected to "stop-and-search" practices, identity cards and backpacks are routinely checked in the street, they are put against the walls and frisked, and sometimes they are taken to the policy station without an explanation. These practices happen much more often in areas termed problem neighborhoods and with some boys who happen to have a darker skin colour.

Seven out of 48 participants talk about these police practices: All are male and all are (North) African. These boys and young men are probably targeted because of their gender and ethnicity (both ostensibly visible identity categories). Although police practices are largely invisible in the public debate, they contribute to the lived experience of young urbanites to such an extent that riots and other violent eruptions should be understood against this backdrop (Fassin, 2013; Schneider, 2015). In fact, quite some participants from these "problem" neighborhoods refer to the behavior of "cowboy" policemen from special units, or to those policemen cruising through the neighborhood never leaving their vans. So young people who are more sceptical about control are also those that are confronted on a regular (almost daily) basis with control, stigma, and ethnic profiling. Conversely, young people with more relaxed or positive attitudes toward surveillance, like those sitting in the busy Jourdan square, are probably seldom confronted with the effects of stigmatization and everyday control.

In orde to understand the total range of control infrastructures, we should also pay attention to ordinary objects such as street furniture, fences, benches, and so on. Here, visibility plays a different role: These objects are of course visible, literally, but the ambiences they produce exert an invisible power on passersby which may be repelling or seductive (Allen, 2006). The effects of these atmospheres are often felt rather than consciously registered. These ordinary objects, however, shape behavior and interactions in public space. In terms of formal control, we cannot call Brussels a "militarised city" (Davis, 1992), but it is home to a jungle of fences, signs, barriers, 
poles, and bollards; to shuttered windows in dilapidated houses; to improvised interventions by residents; and to graffiti-clad street furniture. "Ordinary" objects produce atmospheres, like shadows cast onto passersby, which may trigger affects such as belonging or threat (Kärrholm, 2007). They have an impact on people's movement, interaction, and activities (e.g., Duff, 2010). Atmospheres of familiarity among acquaintances, for instance, have an impact on the development of intercultural tolerance (Wise, 2016).

For example, fences are usually erected to keep intruders out. This seems to be the case in the child care facility in Kuregem on the Lemmens Square. Here, fences, barbed wire, and CCTV cameras target the "delinquent youth" and their alleged drug trade in the square. However, with these fences, the owners or managers of the facility are not only preventing people from coming in, but they also convey a message. As James (2015) puts it, in a study of a youth club in East London being fenced off and consequently being the object of vandalism, "The real purpose of the fence was not to physically prevent entrance to the site but - like the gated community - to make a statement of force, construct a threat and locate a moral territory" (p. 62), like a shadow cast outside the borders of the premises and into the neighborhood.

Fences play another role in and around the high-rise estate of Peterbos. Interestingly, the young participants from that neighborhood are positive about the presence of these artefacts. One would assume that these barriers would symbolise a restriction to young people's movement away from the neighborhood, like the bars to a cage. However, they talk about fences as objects protecting them from the outside world. Thus, barriers can generate feelings of cosiness and safety; they can become place-making agents.

At the same time, by fencing off and closing down large empty spaces - which could of course be an asset to young people in dense environments - bits and pieces are torn from their personal, physical, or symbolic geographies. Temporary barriers become definitive, while physical boundaries become mental boundaries (Lynch, 1981). The same goes for the benches that were removed, "and not because they were worn out" (Alae, 18, male). It was an act directly aimed at limiting the leisure options of local youth. With the removal of these benches, not only physical infrastructure but also an affective and social function is removed from their local ecology.

Considering the space shortage in Brussels, on the one hand, and the legion closed off or vacant lots, on the other, one would expect young people fighting for a place of their own, to be appalled or angry. That is not the case. With the exception of the story told by two 11-year-olds seeking a secret spot for themselves, not one teenager or young adult talks about trespassing or disrespecting property and fencing. One reason might lie in the fact that fences, benches, and many other ordinary objects, while being ostensibly part of an ambient power regime, are felt rather than understood. Their power is invisible but tangible. Another reason might lie in the role of social expectation, as it oozes from the home, school, and other milieus of socialization right into public space. As Franck and Stevens (2006) put it, "Physical barriers and locks provide the most obvious controls on the use of space, but an individual's behavior is also constrained by what they think is appropriate, admissible, or possible" (p. 11).

The same goes for some other ordinary objects, such as prickly bushes planted next to the first-floor windows of the Peterbos primary school, street-level windows that are shuttered, or entrances that are boarded with plywood in Kuregem. Also graffiti is mentioned. To write graffiti is an act of appropriation, a temporary act of privatizing something that is public. Alae (18, male) argues, "We have never destroyed . . . anything in the neighborhood. It's our neighborhood, so what would be the point in doing that?" While vandalizing one's own neighborhood clearly is ridiculous to these boys, to tag and write initials in the halls of the apartment buildings is something entirely different. That is a micropolitical expression of ownership and belonging, which is in many cases directed toward those others who are to feel unwelcome. Boys in the Peterbos and Chicago areas, for instance, also talk about nicknames and postal codes sprayed against walls in the city, as advanced signifiers of the actual territorial border of their own neighborhood. 
To conclude this section, it is clear that control, as a regime of visibility, plays an important role in the behavior of and interactions in public space. However, on the basis of the findings about youth in Brussels' public spaces, we cannot underestimate the role played by rules and codes, by social expectation, and by the ambience exerted by ordinary objects. These latter forms of control are much less visible. And even though they might work on an unconscious and invisible level, they are at least as effective. This nuances the importance of visibility as it is sometimes treated in surveillance and control studies. Although we clearly and increasingly live in a visual world, affective forces that are largely invisible remain important in influencing our behavior in public space (and elsewhere).

\section{Recognition as a Regime of Visibility}

Young people overtly appropriate public space-by claiming a hanging spot or tagging initials on walls and benches - and even engage in their own forms of exerting control. Young people's claim of spaces of their own is often described in overtly political terms such as resistance, protest, and empowerment. In Brighenti's (2007) terminology, we can refer to visibility as recognition - the will of youngsters to claim their place, the claim of the right to the city, and the production of a set of rules and codes of their own making. Here, I want to argue that we need to move beyond an idealized account of young people negotiating top-down, adult-, and state-controlled regimes. They use their visibility as a means to exert power and produce control of their own. To make this point, I will discuss the micropolitical behavior taking place in hanging spots.

Contrary to some public space scholars, I would like to argue that young people do not necessarily prefer to sit outside the adult gaze. Often, on the contrary. It seems that young people want to claim spots that are also frequented by adults: To be in such a central meeting point means that youngsters are not only visible in public but rather that they are the public. It is no coincidence that in the process of growing up, public space occupies a special place: Due to the relative freedom and high diversity youngsters will experience there, it is an excellent locus for experiment, for the invention and negotiation of their own rules, and for developing what Cahill (2000) calls "street literacy."

At the same time, they prefer to distance themselves from other users, particularly from other age-groups (the older teenagers in the skate park, the elderly in the Sint-Antonius Square, or the young families in Hap Park), either spatially or temporally. Put in another way, although they like to be in the middle of the excitement, it seems young people, and especially boys, prefer to dominate the places they are occupying. In such instances, transgression is not a guerrilla-like tactic against the dominant mode of control; it is the dominant mode: "[o]ne of the central ironies of routine transgression is that its agents tend to be the ones who feel they have power within - perhaps even dominate - their chosen geography of play and resistance" (Bonnett, 1996, p. 29). Luckily for them, other users usually make no fuss about this: "When we sit there, we want to be left alone. The park is big enough; they will not necessarily come sit next to us" (Jihane, 17, female).

In this appropriated space, young people engage in theatrical behavior toward other users and passersby (Goffman, 1963, 1971). This theatre is micropolitical, since they are defending their right to be in public - the right of presence, use, action, and modification (Lynch, 1981) — and the framework of rules of their own device. Often, the message of ownership is symbolically conveyed through loud conversation and ostentatious behavior. In general, this type of interaction is rather peaceful: Young people avoid contact and conflict as a rule of thumb.

The football pitch near the Ieper tram stop in the Chicago neighborhood is the result of an actual political stance undertaken by local youth. Some years ago, the city council decided to transform it into a basketball field, which was received by the youngsters as a declaration of war. 
None of them were into basketball, and as a football field it was very popular, so why change it? The decision was interpreted as a gesture of discrimination, one that seemed to signal the city council's aversion against Arab or Maghreb kids playing in the neighborhood. After much protest, the situation was restored. The place became literally a space of representation and contestation in their geographies. In a remarkable inversion, also, the act of abandoning a popular hanging spot can be micropolitical. After the Sint-Antonius Square in Jacht-Jourdan was refurbished, young people decided to hang out elsewhere as if to signal that a hanging spot does not let itself be designed by municipal councils.

Interesting are also those spaces we would ordinarily call quasi- or semipublic. Hicham and Cheb Khaled (both 18, male) like to go to the local snack bar because they know the owner. This place is rendered more "public," because young people are allowed to hang out under the canopy without consumption being mandatory. But such quasi-public spaces are not easily claimed, adapted, or contested, which is why some young people avoid commercial areas. Hicham (18, male), for instance, draws attention to the presence of private security in such places. Several others mention the fact that shopping streets or malls are simply places to act functionally, no place for social behavior or loitering.

In the micropolitics of the hanging out spot, the functionality of these places' design is transformed to better serve their needs. Since adults initiate the design and maintenance of public space, young people's improper use of such places can be, or perhaps is by definition, an act of defiance or protest. In Jacht-Jourdan, between two entrances of the train station on the esplanade in front of the European Parliament, young people transform a bike depot into a hammock; others sit with their backs against the shiny glass of the train station. They lie or sit there as if mocking the glimmering symbols of state authority around them, as an ostentatious gesture toward policemen, security guards, and CCTV cameras. The environment of the European Parliament is heavily regulated, surveilled, and policed, but it turns out these young people do not mind at all.

The micropolitics of hanging out also imply that publicness is effectively transformed. A group of young people produce a bubble of familiarity with a strong binary nature: It is welcoming for those inside the bubble, but it is also exclusionary for those outside. The space being claimed is no longer accessible for others. To be in public or to be part of the public, publicness itself is obliterated. Rather than powerless victims, young people are active users of power in their "territorial tactics," as Kärrholm (2007) calls it (see also de Certeau, 1984). This exposes the paradoxical nature of publicness to the fullest. To be truly social, young people need to be asocial: Establishing a territory goes hand in hand with the erection of boundaries and the exclusion of others. As Németh (2012) puts it, "Publicness is always subjective: whereas some might feel a space full of homeless persons is 'truly public,' this sight might drive other users away" (p. 813).

Much of the hanging out behavior of young people is innocuous. But the fact remains that their gathering of bodies affects the feelings of passersby, residents, or outsiders, and potentially, it also alters their behavior. In neighborhoods with a strong ambience of familiarity, the same phenomenon occurs on a larger scale. For instance, several young people report that they feel uneasy in neighborhoods where they don't know anybody, where they feel out of place. "Those in Molem are crazy," Souhail $(17$, male) says about the inhabitants of another neighborhood.

This becomes very tangible when discussing the gendered patterns of public space behavior among Brussels youth. Girls and young women explain that they have limited spatial freedom or say that they prefer to stay at home much more often than boys and young men. Once outside, there is another difference between these genders. As Faiza (18, female) puts it, "Girls do something when they leave the house, where boys do nothing and hang out." Often, this translates into girls leaving the neighborhood entirely, in order to go shopping with friends. Curiously, most young men are largely unaware of this gender pattern. 
Anneke ${ }^{4}$ : Do you have the feeling that girls are allowed the same as boys?

Kamal (18, male): How do you mean "allowed"?

Anneke: To go out in the weekend, to meet with friends, to go outside . . .

Kamal: I think so, yes.

The gendered use of public space can be partly understood as the result of ambiences of familiarity that are effectively and affectively produced by boys and men present in public space. This translates into separate effects: control (toward women) and belonging (for men). The following discussion is enlightening:

Bérénice (18, female): Boys don't like leaving the neighborhood. But we like to shop.

Me: What else could be a reason for the difference? Does it have something to do with feelings of security, perhaps?

Hicham (18, male): Reputation. The reputation of the girl.

Julia (18, female): They keep an eye on girls. We are not supposed to be in public space. That's different for boys, for them that's okay, they're just boys.

Mourad (18, male): I think girls don't like to hang around in their own neighborhood, because the boys would see their friends.

This dialogue seems to indicate that a regime is set up to control girls and women through notions such as "reputation" and (cultural or other) gendered prescriptions about "acceptable" or expected behavior. This reminds very strongly of Merry's (1984) research of gossip and "reputational control" in the context of close-knit communities. This might have a cultural or religious component, as Nouhaila (19, female) remarks,

Parents who see their son hanging out will not mind that much, while a girl who's always outside, that is a problem. Maybe it's a cultural thing, or a religious thing, but a girl cannot hang out outside constantly. That's impossible.

But at the same time, we must be aware of the "false exceptionalism" of such a phenomenon, as social control also takes places in other ethnic communities.

The rationale behind such a dynamics of reputational control is put even more sharply in this following discussion:

Me: Do you think there are families in which boys have more freedom than girls?

Ahmed (18, male): That's normal.

Bilal $(25$, male): But why?

Ahmed (18, male): Because when they hang out they will become a whore.

Young men in these neighborhoods with a vibrant street life generally like the friendly atmosphere of familiarity; in fact they are co-creators of the ambiance. On young women, this will usually have another effect. They may feel more inclined to alter their behavior in order to avoid the male stare or avoid being in male-dominated space. Nouhaila (19, female) says she doesn't mind the presence of boys in the Chicago neighborhood hanging out on street corners because she knows them personally. Interestingly, Chaimaa (21, female) avoids walking through the neighborhood because of that same reason. Angela Louis $(19$, female) talks about how she navigates the streetcrosses it to avoid being talked to. Gzifa (18, female) says that she listens to her mp3-player when walking between the tram stop and the church in a neighborhood where she feels unsafe.

Among young Muslim women an extra layer can be added to the analysis. Here, we can refer to the important role of visibility in the social structuring of behavior of female Muslims, which 
presents an alternative view on "public" space (Mazumdar \& Mazumdar, 2001). In general, Muslim women are not expected to be in the same room as males who could be marriage candidates. In public space, this prescription translates into gendered, temporal, and spatial patterns. Coping with this cultural reality, Muslim women may choose to cover themselves and wear a veil. This too transforms publicness - that is, an extra layer is wrapped around that person, as a "territory of the self" (Goffman, 1971). Veiling is used as a defence tactic against the male gaze, but it is also an emancipatory tool. Some young women make a conscious decision to wear the veil (as opposed to their mothers and grandmothers wearing it out of tradition or habit-from the Latin root habitus meaning "appearance"), which allows them to fully partake in "Western" society: to play theatre, study at university, or work as a volunteer in a youth club.

For this reason, it was received with incomprehension when a secondary school in the Chicago neighborhood decided to ban headscarves. What is wrong with women expressing their independence and individuality, they wondered. The nonverbal, embodied communication of the veil conveys information, a micropolitical act: "It disobeys both traditional and secular ways of imagining self-emancipation and becoming public" (Göle, 2002, p. 188). The headscarf ban is conceived as a contradiction with Western values of individual expression and religious freedom. Chaimaa (21, female), reflecting on this topic, argues that rather than that these young Muslims should be asked to better integrate; it is those people who still consider Belgium as an inherently White territory who are in need of integration.

At the same time, several young Muslim women acknowledge that wearing a veil can expose them and can actually attract gazes rather than make them invisible. As Listerborn (2015) notes, such practices may cause them to stand out and become a victim of violence, which will reinforce certain spatial and social practices. As a result, these intersecting forms of oppression "keep them in their place," which inevitably makes it much harder for young women to negotiate conformity and resistance (Ehrkamp, 2013).

\section{Conclusion}

Many of the practices studied in this article transform the publicness of public spaces. These spaces are no longer entirely accessible, rules of stranger interaction are modified, and the diversity of users and uses is obliterated and replaced by a parochial bubble. These transformations all play with visibility and invisibility: being visible by appropriation or making visible through control. The main point in this article is that these modes of visibility are heavily intertwined, which is why the analysis takes us full circle.

Young people deal with control in varied ways, depending on characteristics such as age, gender, and ethnicity, and depending on a case history of daily control, stigma, and targeted policy practices. But young people are not only victims of control. Sometimes they claim a space in a forceful way, while excluding others. This is the case in the theatrical play engaged in by young people in their hanging spot. This is also what we see when boys and young men hang out in the square of their home neighborhood exerting an influence on passersby. In the "solidarity circle" (Sloterdijk, 2014) of these men, micropolitics is one of belonging toward insiders and of exclusion toward outsiders.

This becomes clear when studying the gendered nature of public space: Girls prefer to stay at home or feel that they have to use certain defence tactics in order to deal with the male gaze and the reputational control exerted through informal social control and gossip. Particularly, but not only, among Muslim girls, such defence tactics may take the form of "dressing appropriately" and veiling practices. In the dominant discourse, these pieces of textile are seen as oppressive, used to keep women in their place. However, they also allow these young women to partake in public life. Furthermore, these girls feel that they make a conscious choice in distinguishing themselves from both the traditional world of their home and the secular world of the youth club, university, leisure club, and job market. 
To consider certain practices of young people in public space as micropolitical, using visibility as a perspective, allows us to move beyond idealized, binary understandings of top-down control and bottom-up acts of resistance. The regimes of visibility treated in this article- recognition and control - are contradicted, pried open, and shattered. Rather than two opposing outcomes, as Brighenti (2007) seems to suggest, I would present them as vectors in a circular motion; and the circle never stops. Some acts can be understood both as recognition or as control, one can transform into the other, or they can be both at the same time.

There is also no straightforward connection between the visibility of control/recognition and the degree in which occupants of public space are effectively controlled/recognized. Following Allen's (2006) analysis, I want to advocate for a further exploration of the less visible but ever more "impalpable" affects produced by ordinary objects and of ambiences in the street, both of which are often overlooked in surveillance and public space studies (see De Backer and Pavoni, 2018). For this, we need a phenomenological eye: "Since the total visible is always behind, or after, or between the aspects we see of it, there is access to it only through an experience which, like it, is wholly outside of itself" (Merleau-Ponty, 1968, p. 136).

\section{Declaration of Conflicting Interests}

The author(s) declared no potential conflicts of interest with respect to the research, authorship, and/or publication of this article.

\section{Funding}

The author(s) disclosed receipt of the following financial support for the research, authorship, and/or publication of this article: The author received a grant from FWO, the Flemish fund for seicntific research (grant number: G063312N).

\section{Notes}

1. In the literature, definitions for "public space" are legion. Carr, Francis, Rivlin, \& Stone (1992) and Carmona, Magalhaes, and Hammond (2008) emphasize accessibility as the central characteristic of public space, while Walzer (1986) and Sennett (1970) stress the fact that within public space we are by definition among strangers, people who are not our relatives or friends. Lofland (1998) uses the same criterion to distinguish the public from the parochial and private realms. In her seminal work on lower Manhattan, Jane Jacobs (1961) treats public space as a lively place filled with a large diversity of uses and users. For this author, diversity is essential to constitute something truly public. Hatuka and Toch (2017), in their research on online and off-line public spaces, find indications that control plays a crucial role in defining publicness.

2. Mon Espace https://www.youtube.com/watch?v $=$ oFubRsQ5k-M

3. The data on unemployment used in this section are taken from the website http://wijkmonitoring.brussels, which collects all the latest data from the Brussels employment agency Actiris and the Belgian statistics agency Statistics Belgium. The latest unemployment data were collected in 2012.

4. Colleagues Anneke and Els have helped me with some interviews in the Sint-Guido secondary school, for which I am of course very grateful.

\section{References}

Allen, J. (2006). Ambient power: Berlin's Potsdamer Platz and the seductive logic of public spaces. Urban Studies, 43, 441-455.

Arendt, H. (1998). The human condition (2nd ed.). Chicago, IL: University of Chicago Press. (Original work published 1958)

Bonnett, A. (1996). The transgressive geographies of daily life: Socialist pathways within everyday urban spatial creativity. Transgressions, 2, 20-37.

Brighenti, A. M. (2007). Visibility: A category for the social sciences. Current Sociology, 55, 323-342.

Brighenti, A. M. (2008). Democracy and its visibilities. In K. Haggarty \& M. Samatas (Eds.), Surveillance and democracy (pp. 51-68). New York, NY: Routledge. 
Brighenti, A. M. (2010a). At the wall: Graffiti writers, urban territoriality, and the public domain. Space and Culture, 13, 315-332.

Brighenti, A. M. (2010b). The publicness of public space: On the public domain. Quaderno, 49. Università degli studi di Trento: Dipartimento di Sociologia e Ricerca Sociale.

Brown, S. (1998). What's the problem girls? CCTV and the gendering of public safety. In C. Norris, J. Moran \& G. Armstrong (Eds.), Surveillance, closed circuit television and social control (pp. 207-220). Aldershot, England: Ashgate.

Cahill, C. (2000). Street literacy: Urban teenagers' strategies for negotiating their neighbourhood. Journal of Youth Studies, 3, 251-277.

Cancellieri, A., \& Ostanel, E. (2015). The struggle for public space. City: Analysis of Urban Trends, Culture, Theory, Policy, Action, 19, 499-509.

Carmona, M., Magalhaes, C. D., \& Hammond, L. (2008). Public space: The management dimension. London, England: Routledge.

Carr, S., Francis, M., Rivlin, L. G., \& Stone, A. M. (1992). Public space. Cambridge, England: Cambridge University Press.

Coaffee, J., O'Hare, P., \& Hawkesworth, M. (2009). The visibility of (in)security: The aesthetics of planning urban defences against terrorism. Security Dialogue, 40, 489-511.

Cook, I. R., \& Whowell, M. (2011). Visibility and the policing of public space. Geography Compass, 8, 610-622.

Corijn, E., \& Vloeberghs, E. (2009). Brussel! Brussels, Belgium: VUB Press.

Coverley, M. (2010). Psychogeography. Harpenden, England: Pocket Essentials.

Davis, M. (1992). Fortress Los Angeles: The militarization of urban space. In M. Sorkin (Ed.), Variations on a theme park: The new American city and the end of public space. New York, NY: Noonday Press.

De Backer, M., \& Pavoni, A. (2018). Through thick and thin: Young people's affective geographies in Brussels' public space. Emotion, Space and Society, 27, 9-15.

de Certeau, M. (1984). The practice of everyday life (S. F. Rendall, Trans.). Berkeley: University of California Press.

Debord, G. (1958). Theory of the derive. Internationale situationniste, 2. Retrieved from http://www.cddc. vt.edu/sionline/si/theory.html

Dixon, J., Levine, M., \& McAuley, R. (2006). Locating impropriety: Street drinking, moral order, and the ideological dilemma of public space. Political Psychology, 27, 187-206.

Duff, C. (2010). On the role of affect and practice in the production of place. Environment and Planning D: Society and Space, 28, 881-895.

Ehrkamp, P. (2013). "I've had it with them!' Younger migrant women's spatial practices of conformity and resistance. Gender, Place \& Culture, 20, 19-36.

Fassin, D. (2013). Enforcing order: An ethnography of urban policing. Cambridge, England: Polity Press.

Foucault, M. (1977). Discipline and punish: The birth of the prison. London, England: Penguin.

Franck, K. A., \& Stevens, Q. (Eds.). (2006). Loose space: Possiblity and diversity in urban life. Abingdon, England: Routledge.

Frers, L., \& Meier, L. (2017). The limits of resistance in public space. Space and Culture, 20, 124-126.

Goffman, E. (1963). Behavior in public places: Notes on the social organization of gatherings. New York, NY: Free Press.

Goffman, E. (1971). Relations in public: Microstudies of the public order. New York, NY: Basic Books.

Göle, N. (2002). Islam in public: New visibilities and new imaginaries. Public Culture, 14, 173-190.

Göle, N. (2011). The public visibility of Islam and European politics of resentment: The minarets-mosques debate. Philosophy \& Social Criticism, 37, 383-392.

Gordon, N. (2002). On visibility and power: An Arendtian corrective of Foucault. Human Studies, 25, $125-145$.

Hatuka, T., \& Toch, E. (2017). Being visible in public space: The normalisation of asymetrical visibility. Urban Studies, 54, 984-998.

James, M. (2015). Urban multiculture: Youth, politics and cultural transformation in a global city. Basingstoke, England: Palgrave Macmillan.

Kärrholm, M. (2007). The materiality of territorial production: Conceptual discussion of territoriality, materiality and the everyday life of public space. Space and Culture, 10, 437-453. 
Koskela, H. (2000). "The gaze without eyes": Video-surveillance and the changing nature of urban space. Progress in Human Geography, 24, 243-265.

Langegger, S., \& Koester, S. (2016). Invisible homelessness: Anonymity, exposure, and the right to the city. Urban Geography, 37, 1030-1048.

Listerborn, C. (2015). Geographies of the veil: Violent encounters in urban public spaces in Malmö, Sweden. Social \& Cultural Geography, 16, 95-115.

Lofland, L. H. (1998). The public realm: Exploring the city's quintessential social territory. London, England: Aldine Transaction.

Lofland, J., Snow, D., Anderson, L., \& Lofland, L. H. (2006). Analyzing social settings: A guide to qualitative observation and analysis (4th ed.). Boston, MA: Wadsworth Cengage Learning.

Lynch, K. (1981). A theory of good city form. Cambridge: MIT Press.

Massey, D. (1994). Space, place and gender. Cambridge, England: Polity Press.

Mazumdar, S., \& Mazumdar, S. (2001). Rethinking public and private space: Religion and women in Muslim society. Journal of Architectural and Planning Research, 18, 302-324.

Merleau-Ponty, M. (1968). The visible and the invisible. Evanston, IL: Northwestern University Press.

Merry, S. (1984). Rethinking gossip and scandal. In D. Black (Ed.), Towards a general theory of social control: Fundamentals (Vol 1, pp. 271-302). New York, NY: Academic Press.

Millbank, J. (2002). "Gender, visibility and public space in refugee claims on the basis of sexual orientation. Journal for Social Justice, 1, 725-742.

Németh, J. (2012). Controlling the commons: How public is public space? Urban Affairs Review, 48, 811-835.

Newman, O., (1972). Defensible space: Crime prevention through urban design. New York, NY: Macmillan.

Podmore, J. A. (2001). Lesbians in the crowd: Gender, sexuality and visibility along Montréal's Boul. St-Laurent. Gender, Place \& Culture, 8, 333-355.

Schneider, C. (2014). Police power and race riots: Urban unrest in Paris and New York. Philadelphia: University of Pennsylvania Press.

Sennett, R. (1970). The uses of disorder: Personal identity and city life. New York, NY: Knopf.

Sloterdijk, P. (2014), Globes Spheres Volume II: Macrosphereology. Los Angeles: Semiotext(e)

Thompson, J. B. (2005). The new visibility. Theory, Culture \& Society, 22(6), 31-51.

Travlou, P. (2003). Teenagers and public space: Literature review. Edinburgh, Scotland: OpenSpace. Retreived from http://www.openspace.eca.ed.ac.uk/wp-content/uploads/2015/10/Teenagers-andPublic-Space-literature-review.pdf

Valentine, G. (1995), Out and about: geographies of lesbian landscapes. International Journal of Urban and Regional Research. 19(1): 96-111.

Walzer, M. (1986). Pleasures and costs of urbanity. Dissent, Fall, 470-475. Retrieved from https://www. dissentmagazine.org/pdfs/walzerurban.pdf

Wise, A. (2016). Becoming cosmopolitan: Encountering difference in a city of mobile labour. Journal of Ethnic and Migration Studies, 42, 2289-2308.

\section{Author Biography}

Mattias De Backer is a postdoctoral researcher at the Leuven Institute of Criminology (KU Leuven, Belgium) and research coordinator of a multi-university and multidisciplinary research project on "radicalisation" among Muslim youngsters in Brussels and Verviers (CONRAD). He holds a Master's degree in Philosophy, an Advanced Master in Urban Studies and a $\mathrm{PhD}$ in Criminology. His $\mathrm{PhD}$ was on young people, public space and identity in Brussels (VUB). His main interests are in the fields of urban studies, social geography and criminology, particularly in topics concerning urbanism, public space, youth, migration and diversity, space and place, gender and feminism and post-structuralist philosophy. 